Disclosure of Interests: Alexis Ogdie Shareholder of: Amgen, Novartis, Pfizer Inc, Grant/research support from: Novartis, Consultant of: AbbVie, Amgen, Bristol-Myers Squibb, Celgene, Corrona, Eli Lilly, Novartis, Pfizer Inc, Luke Schmerold Consultant of: Astellas, Helsinn Therapeutics, Janssen, Pfizer Inc, Employee of: SmartAnalyst Inc, William Tillett Grant/research support from: AbbVie, Celgene, Eli Lilly, Janssen, Novartis, Pfizer Inc, UCB, Consultant of: AbbVie, Amgen, Celgene, Lilly, Janssen, Novartis, MSD, Pfizer Inc, UCB, Speakers bureau: AbbVie, Amgen, Celgene, Lilly, Janssen, Novartis, Pfizer Inc, UCB, Rebecca Germino Shareholder of: Pfizer Inc, Employee of: Pfizer Inc, Joseph C Cappelleri Shareholder of: Pfizer Inc, Employee of: Pfizer Inc, Pamela Young Shareholder of: Pfizer Inc, Employee of: Pfizer Inc

DOI: 10.1136/annrheumdis-2020-eular.982

\section{AB0812 IS THE VISCERAL ADIPOSITY INDEX ASSOCIATED WITH THE PRESENCE OF CARDIOVASCULAR RISK SCORES AND COMORBIDITY IN PSORIATIC DISEASE?}

A. Omma ${ }^{1}$, F. Erden ${ }^{1}$, S. Colak ${ }^{2}$, S. Can Sandikci ${ }^{3}$, T. Omma ${ }^{4}$, I. Kasım', A. Ozkara ${ }^{1}$, A. Erden5. ${ }^{1}$ Ankara City Hospital, Ankara, Turkey; ${ }^{2}$ University of Health Sciences, Gulhane Medicine Faculty, Ankara, Turkey; ${ }^{3}$ Ankara Diskapi Yildirim Beyazit Training and Research Hospital, Ankara, Turkey; ${ }^{4}$ Ankara Training and Research Hospital, Ankara, Turkey; ${ }^{1}$ Ankara City Hospital, Ankara, Turkey

Background: Psoriatic disease (PsD) is a chronic immune-mediated inflammatory disorder and predominantly involves the skin and joints. There is a better known relationship between the severity of PsD with some comorbidities such as metabolic syndrome, cardiovascular disease and obesity. Visceral Adiposity Index (VAI) has been shown to be an important marker, gender- dependent for insulin resistance, adipose tissue function and distribution.

Objectives: The aim of this study was to evaluate the relationship between the $\mathrm{VAI}$ and cardiovascular risk scores of patients with psoriatic arthritis.

Methods: This study was conducted with 101 PsD patients who fulfilled the classification criteria for Psoriatic Arthritis (CASPAR) criteria and 98 healthy subjects. Demographic and clinical data were recorded. Disease activity was evaluated with the Health Assessment Questionnaire (HAQ), Disease Activity Index for Psoriatic Arthritis (DAPSA), Bath Ankylosing Spondylitis Disease Activity Index (BASDAI), Bath Ankylosing Spondylitis Disease Activity Index (BASFI) and Psoriasis Area Severity Index (PASI). The SCORE, Framingham index, metabolic syndrome (MetS), Body mass index (BMI) and VAI values of the patients and the VAI values of the healthy subjects were calculated.

Results: Mean BMI $\left(\mathrm{kg} / \mathrm{m}^{2}\right)$ was calculated as 29.635 .66 . According to the SCORE measurements, $53(52.5 \%)$ patients were at low risk, $45(44.6 \%)$ at moderate risk, and $3(3 \%)$ at high risk. No patients were at very high risk. According to the Framingham score, 72 patients (71.3\%) were at low risk, 22 patients $(21.8 \%)$ at intermediate risk and 7 patients $(6.9 \%)$ at high risk. The risk was found to be statistically significantly higher in the PsD group compared to the healthy control group in respect of metabolic syndrome, obesity $(B M I>30)$ and VAI levels $(p<0.05)$. Significantly higher VAI levels were determined in PsD patients with metabolic syndrome, BMI> 30 (obesity), diabetes mellitus and hypertension compared to without these comorbidities $(p<0.05)$. A statistically significant correlation was determined between low and moderate risk Framingham score, and the VAI levels of PSD patients. Correlations were determined between disease activity and metabolic and cardiovascular risks of patients. A weak correlation was observed between VAl levels and the Framingham score (Table).

Table. Correlations ( $r$ ) between disease activity and metabolic and cardiovascular risks of patients

\begin{tabular}{|c|c|c|c|c|c|c|c|c|}
\hline Parameters & BASDAI & PASI & DAPSA & BASFI & HAQ & VAI & SCORE & $\begin{array}{c}\text { Framingham } \\
\text { risk score }\end{array}$ \\
\hline $\begin{array}{r}\text { Framingham } \\
\text { risk score }\end{array}$ & 0.02 & 0.095 & $0.285^{\star *}$ & $0.202^{\star \star}$ & 0.067 & $0.299^{\star \star}$ & 0.523 & 1 \\
\hline SCORE & -0.079 & -0.026 & 0.095 & 0.065 & -0.01 & 0.058 & 1 & $0.523^{\star *}$ \\
\hline VAI & 0.128 & 0.192 & 0.101 & 0.105 & 0.019 & 1 & 0.058 & $0.299^{* *}$ \\
\hline HAQ & 0.129 & 0.135 & $0.421^{\star \star}$ & $0.284^{\star \star}$ & 1 & 0.019 & -0.01 & 0.067 \\
\hline BASFI & $0.764^{\star \star}$ & 0.14 & $0.484^{\star \star}$ & 1 & $0.284^{\star *}$ & 0.105 & 0.065 & $0.202^{*}$ \\
\hline DAPSA & $0.462^{\star \star}$ & $0.341^{\star \star}$ & 1 & $0.484^{\star \star}$ & $0.421^{\star \star}$ & 0.101 & 0.095 & $0.285^{\star \star}$ \\
\hline PASI & 0.092 & 1 & $0.341^{\star *}$ & 0.140 & 0.135 & 0.192 & -0.026 & 0.095 \\
\hline BASDAI & 1 & 0.092 & $0.462^{\star *}$ & $0.764^{\star *}$ & 0.129 & 0.128 & -0.079 & 0.024 \\
\hline
\end{tabular}

Abbreviation; VAI: Visceral Adiposity Index, SCORE: Systematic Coronary Risk Evaluation Index, Health Assessment Questionnaire (HAQ), Disease Activity Index for Psoriatic Arthritis (DAPSA), Bath Ankylosing Spondylitis Disease Activity Index (BASDAI), Bath Ankylosing Spondylitis Disease Activity Index (BASFI) and Psoriasis Area Severity Index (PASI). * $p<0.05$, ${ }^{* *} \mathrm{p}<0.001$
Conclusion: Patients with psoriasis are more susceptible to obesity and other diseases such as metabolic syndrome, dyslipidemia, cardiovascular diseases, insulin resistance and diabetes. Therefore, control of bodyweight in PsD patients is important for management of the disease. Since VAI can be calculated simply from routinely taken measurements, the VAI level can be used to determine cardiovascular risk and VAI may also provide clues about comorbidities in patients with newly diagnosed PsD.

Disclosure of Interests: None declared

DOI: 10.1136/annrheumdis-2020-eular.3809

AB0813
GUSELKUMAB-TREATED PATIENTS ACHIEVED
CLINICALLY MEANINGFUL IMPROVEMENT IN
SYSTEMIC SYMPTOMS AS MEASURED WITH PROMIS
INSTRUMENT: RESULTS FROM PHASE-3 PSORIATIC
ARTHRITIS TRIAL DISCOVER 1

A. M. Orbai ${ }^{1}$, L. C. Coates ${ }^{2}$, A. Deodhar ${ }^{3}$, P. Helliwell ${ }^{4}$, C. T. Ritchlin ${ }^{5}$, A. Kollmeier ${ }^{6}$, E. C. Hsia ${ }^{6,7}$, X. L. Xu' ${ }^{6}$, S. Sheng ${ }^{6}$, B. Zhou ${ }^{6}$, C. Han ${ }^{6} .{ }^{1} J o h n s$ Hopkins Univ School of Med, Baltimore, United States of America; ${ }^{2}$ Oxford Univ, Oxford, United Kingdom; ${ }^{3}$ Oregon Health \& Science U, Portland, United States of America; ${ }^{4} U$ of Leeds, Leeds, United Kingdom; ${ }^{5} U$ Rochester Med Ctr, Rochester, United States of America; ${ }^{6}$ Janssen Research \& Development, LLC, Spring House, United States of America; ${ }^{7} \mathrm{U}$ Penn Med Ctr, Philadelphia, United States of America

Background: Patients (pts) with psoriatic arthritis (PsA) experience broad systemic symptoms including pain, fatigue, depression, sleep disturbance, poor physical function, and diminished social participation.

Objectives: DISCOVER 1 is a Phase 3 trial (NCT03162796) evaluating the efficacy and safety of guselkumab (GUS), an anti-interleukin 23 inhibitor that binds to the p19-subunit of IL-23, in pts with active PsA. PROMIS-29 (Patient-Reported Outcomes Measurement Information System-29), a validated generic health instrument, ${ }^{1}$ assessed the treatment effect of GUS on symptoms in pts with PsA.

Methods: Pts with active PsA despite nonbiologic DMARDs were enrolled, and $\sim 30 \%$ of pts could have previously received $\leq 2 \mathrm{TNFi}$. Pts were randomized (1:1:1) to subcutaneous GUS $100 \mathrm{mg}$ at Week 0 (W0), W4 then q8W ( $n=127)$, GUS $100 \mathrm{mg}$ q4W $(n=128)$, or PBO $(n=126)$. Concomitant stable use of select cSDMARDs, oral steroids, and NSAIDs was allowed. PROMIS-29 consists of 7 domains (Depression, Anxiety, Physical Function, Pain Interference, Fatigue, Sleep Disturbance, and Social Participation) and a pain intensity 0-10 numeric rating scale (NRS). The raw score of each domain is converted into a standardized T-score with a mean of 50 (general population mean) and a standard deviation (SD) of 10. Higher PROMIS scores represent more of the concept being measured. $A>=5$-point improvement (1/2 SD of T-score) is defined as clinically meaningful. ${ }^{1}$

Results: At baseline, mean PROMIS-29 T-scores for physical function, social participation, sleep disturbance, pain, and fatigue were worse than the general US population. At W24, GUS q8W-treated pts achieved greater improvements from baseline in all PROMIS-29 domains vs PBO $(p<0.05)$ (Table and Fig 1). Results were consistent in the GUS q4W group except for anxiety and sleep disturbance. More pts receiving GUS achieved clinically meaningful improvement vs PBO except for depression and anxiety in the GUS q4W group, which were numerically improved (Fig 2).

Conclusion: Active PSA pts treated with GUS achieved clinically meaningful reduction in symptoms and improvement in physical function and social participation vs PBO at W24.

References:

[1] http://www.healthmeasures.net/score-and-interpret/interpret-scores/ meaningful-change/165-meaningful-change

Table. PROMIS-29 Domain T-Scores Least Square (LS) Mean Change from Baseline

\begin{tabular}{lccc}
\hline & \multicolumn{3}{c}{ LS Mean Change from Baseline } \\
\cline { 2 - 4 } & PBO & GUS q8W & GUS q4W \\
\hline Anxiety & -1.37 & $-3.23^{\star}$ & -2.92 \\
Depression & -0.85 & $-3.4^{\star *}$ & $-2.67^{\star}$ \\
Fatigue & -1.86 & $-4.79^{\star *}$ & $-5.08^{\star *}$ \\
Pain interference & -2.30 & $-5.49^{\star *}$ & $-5.69^{\star *}$ \\
Physical function & 1.34 & $3.89^{\star *}$ & $5.05^{\star *}$ \\
Sleep disturbance & -1.17 & $-3.48^{\star *}$ & -2.46 \\
Social participation & 1.45 & $4.90^{\star *}$ & $4.52^{\star \star}$ \\
Pain intensity & -0.56 & $-1.98^{\star *}$ & $-2.32^{\star *}$ \\
\hline
\end{tabular}

Nominal p-values vs placebo: ${ }^{*}<0.05,{ }^{* *}<0.01$ 